Portland State University

PDXScholar

\title{
A Dynamic Model of the Opioid Drug Epidemic with Implications for Policy
}

Jack Homer

Homer Consulting and MIT

Wayne W. Wakeland

Portland State University, wakeland@pdx.edu

Follow this and additional works at: https://pdxscholar.library.pdx.edu/sysc_fac

Let us know how access to this document benefits you.

\section{Citation Details}

Pre-print citation: Jack Homer and Wayne W. Wakeland. (2020) "A Dynamic Model of the Opioid Drug Epidemic with Implications for Policy." https://archives.pdx.edu/ds/psu/32340 Published version citation: Homer, Jack and Wakeland, Wayne. "A Dynamic Model of the Opioid Drug Epidemic with Implications for Policy." American Journal of Drug and Alcohol Abuse, June 2020. https://www.tandfonline.com/doi/full/ 10.1080/00952990.2020.1755677. Supplemental material (Appendix) at: https://www.tandfonline.com/ doi/suppl/10.1080/00952990.2020.1755677.

This Pre-Print is brought to you for free and open access. It has been accepted for inclusion in Systems Science Faculty Publications and Presentations by an authorized administrator of PDXScholar. Please contact us if we can make this document more accessible: pdxscholar@pdx.edu. 
A Dynamic Model of the Opioid Drug Epidemic with Implications for Policy

\author{
Jack Homer $^{1}$ and Wayne Wakeland ${ }^{2}$ \\ ${ }^{1}$ Homer Consulting and MIT \\ ${ }^{2}$ Portland State University
}

June 2020

Accepted for 2020 Publication:

The American Journal of Drug and Alcohol Abuse (AJDAA) 


\title{
Financial Disclosure and Funding Source
}

The initial version of the model described in this paper was developed under a contract funded by Herc Litigation Services LLC and the law firms of Levin Papantonio and Baron \& Budd. Consulting fees were paid to Homer Consulting and Wayne Wakeland.

\begin{abstract}
Background: The U.S. opioid epidemic has caused substantial harm for over 20 years. Policy interventions have had limited impact and sometimes backfired. Experts recommend a systems modeling approach to address the complexities of opioid policymaking.
\end{abstract}

Objectives: Develop a system dynamics simulation model that reflects the complexities and can anticipate intended and unintended intervention effects.

Methods: The model was developed from literature review and data gathering. Its outputs, starting in 1990, were compared against 12 historical time series. Four illustrative interventions were simulated for $2020-2030$ : reducing prescription dosage by $20 \%$, cutting diversion by $30 \%$, increasing addiction treatment from $45 \%$ to $65 \%$, and increasing lay naloxone use from $4 \%$ to $20 \%$. Sensitivity testing was performed to determine effects of uncertainties. No human subjects were studied.

Results: The model fits historical data well with error percentage averaging $9 \%$ across 201 data points. Interventions to reduce dosage and diversion reduce the number of persons with opioid use disorder (PWOUD) by $11 \%$ and $16 \%$, respectively, but each of these interventions 
reduces overdoses by only $1 \%$. Boosting treatment reduces overdoses by $3 \%$ but increases

PWOUD by $1 \%$. Expanding naloxone reduces overdose deaths by $12 \%$ but increases PWOUD by $2 \%$ and overdoses by $3 \%$. Combining all four interventions reduces PWOUD by $24 \%$, overdoses by $4 \%$, and deaths by $18 \%$. Uncertainties may affect these numerical results, but policy findings are unchanged.

Conclusion: No single intervention significantly reduces both PWOUD and overdose deaths, but a combination strategy can do so. Entering the 2020s, only protective measures like naloxone expansion could significantly reduce overdose deaths.

\section{Background and Purpose}

The epidemic of opioid abuse in the United States started in the late 1990s and is still unabated. The story is well-known: excessive prescriptions, followed by diversion to an illicit market, growing addiction, the shift to heroin, and then the ravages of deadly illicit fentanyl (1-4). The number of persons with opioid use disorder (PWOUD) tripled from 1995 to 2010, rising to more than 2 million (5); and since then has remained stubbornly at that level despite addiction treatment more than tripling from 2003 to 2015 (6). The number of opioid overdose deaths rose from about 8,000 in 1999 , to 21,000 in 2010 , to 48,000 in 2017 (7). Hundreds of thousands have lost their lives to the epidemic, and the estimated economic costs of opioid addiction and death are nearly $\$ 100$ billion per year (8-9).

A variety of policy interventions have been proposed to address the epidemic. These include efforts to control opioid prescribing and dosage strength, to control diversion, to expand and 
improve addiction treatment, and to reduce overdose deaths and other harms (1). Past intervention efforts have had limited success and have sometimes backfired. One example is the introduction of tamper-resistant OxyContin in 2010, which did reduce abuse of that drug but also caused many PWOUD to switch from prescription opioids to heroin (10) - a risky switch given the later widespread fentanyl contamination of heroin. Similarly, there is a concern that efforts to limit prescription and diversion of legal opioids might leave street users more vulnerable to dangerous counterfeit fentanyl pills (1). Even the "obvious" policy of expanding naloxone distribution to reduce overdose deaths has been questioned by some, because it might encourage more opioid abuse $(11,12)$.

A committee of the National Academies of Science, Engineering, and Medicine has recommended that a systems modeling approach be taken to deal with such complexities and policy uncertainties (1). Their report cited modeling work by Wakeland and colleagues (13-14) as a first step in that direction. Other opioid systems frameworks and models have also been presented recently (15-18).

Here we present a new systems model at the U.S. national level that uses the same system dynamics simulation methodology as the original Wakeland work (which traced the epidemic through 2011) but updates and extends beyond the scope of the older model. For example, the new model includes the effects of fentanyl in the illicit markets for prescription opioids and heroin. It can be used to evaluate a wide variety of policy interventions, quantifying their intended and unintended consequences over time. We first describe the model's basic structure and outputs, and then describe the results of illustrative intervention testing using the model. 


\section{Methods}

(An IRB consent process/ethics committee is not applicable. This study did not involve human subjects.)

\section{Model Description}

\section{System dynamics (SD) modeling}

System dynamics was developed in the 1950s and is used to study complex issues of business strategy and public policy. An SD model consists of interlinked differential equations, linear and nonlinear algebraic relationships, and input assumptions. It produces outputs that replicate historical trajectories and projects them into the future, along with the impacts of potential interventions and uncertainties. The approach has been applied to many population health and drug abuse issues (19-22).

SD models typically divide populations of interest into separate compartments or stocks, detailing the flows that go into, between, and out of the stocks.

SD models also include behavioral feedback loops that can cause annual flow rates (also called transition rates) to change predictably over time rather than remaining fixed. For example, new initiates to opioid non-medical use might initially be attracted by the presence of plentiful availability on the street; but a large increase in the number of non-medical users might subsequently cause street availability to diminish, thus limiting further initiation.

The inclusion of such feedback loops distinguishes fully realized SD models from less elaborate model types that assume fixed or exogenous transition rates. Such simpler models have been 
used for studying the opioid epidemic (15-16); but without explicit feedback loops, they cannot systematically anticipate the dynamic consequences of potential interventions.

\section{Model development and overview}

We followed established procedures for SD model development (19). This involved first updating our understanding of the epidemic (beyond the original Wakeland work) based on the latest reports and analysis, including studies of recent trends. From these studies, as well as our own analysis of several online datasets, we developed longitudinal time series starting from as far back as 1990 to the present (23-46). We then developed, through multiple iterations, a dynamic structure (involving stocks, flows, feedback loops, and external factors) capable of explaining the historical trends. We also did extensive sensitivity testing (see online Appendix) to determine what effect uncertainties might have on model outputs looking as much as a decade into the future.

This process resulted in a model (comprising 8 stocks, some 200 algebraic variables, and some 80 input parameters) that conforms with the literature, reproduces a variety of national-level historical trends, and is fit for policy analysis. The model was implemented using Vensim ${ }^{\mathrm{TM}}$ (version 7.3.5), a standard for advanced SD modeling. Full details of the model's structure, equations, and input parameters are presented elsewhere (47). Figure 1 presents an overview of the model's causal structure. Table 1 lists variables for which we assembled longitudinal historical data, including 8 time series used to calibrate model inputs and 12 time series against which model outputs are compared (see online Appendix for data values).

<Figure 1 goes about here> 
$<$ Table 1 goes about here $>$

At the heart of the model are non-medical users (NMUs) of opioids, subdivided into six mutually exclusive stocks defined by two dimensions, the first of which is drug type used: during any given year, some NMUs use prescription opioids (PO) but not heroin, some use heroin but not PO, and some use both PO and heroin. The second dimension is the presence or absence of opioid use disorder (OUD).

Associated with the six NMU stocks are 30 inflows, outflows, and interconnecting flows. These fall into five categories: flows of initiation, becoming addicted, shifting among drug type used (PO and/or heroin), quitting (abstinent for at least one year), and death (from overdose and all other causes).

We quantified the six NMU stocks and their associated flows with the support of data from the National Survey on Drug Abuse and Health (NSDUH), as detailed in Table 1.

\section{PO non-medical use initiation, addiction, and quitting}

One source of PO NMU initiation and addiction is from medical users, those who have scripts and initially use as directed. The number of medical users is modeled based on the number of PO scripts written per month. PO script volume is modeled exogenously reflecting historical values (see Table 1) and projected forward based on population growth and aging; one may also simulate a future policy intervention to reduce script volume. 
Medical users of PO may transition to non-medical use (OUD or non-OUD). But only a minority of new PO NMUs have their own script $(38,43)$, the great majority being "street" initiates who use diverted PO that is shared or obtained on the illicit market.

Street initiates to PO grew from 1990 to the early 2000s, before starting a long and uneven decline. The growth likely occurred for two reasons: first, the snowball effect of social diffusion; and second, a gradual increase in PO availability (and decrease in price) on the street. The decline likely occurred initially because of the fear of overdose: PO NMU overdose deaths nearly tripled from 1999 to 2011 (47). The decline in PO initiation after 2010 was also likely due to availability disruptions (discussed below). Both availability and fear are well-known factors affecting illicit drug initiation $(13,21,38,48)$.

The likelihood of medical users becoming addicted (transitioning to OUD) increases with higher prescribed dose strengths (measured in milligrams of morphine equivalent or MME) (49). Average dose strength (as a proxy for the entire distribution of different dose strengths being prescribed) is modeled exogenously to reproduce the historical MME trend (27-28); one may also simulate a future policy intervention to reduce average prescribed dose strength.

The more common path to PO OUD, rather than from medical use, is through escalation from non-OUD street use. If the relative availability of diverted PO were to grow, the risk of escalation would also increase, because greater accessibility tends to boost frequency of use $(13,50)$.

Our model-based analysis of the historical data suggests that the factors of fear and availability that affected PO initiation also affected rates of quitting among PO NMUs. Another factor 
affecting quitting is medication-assisted treatment (MAT). MAT can boost the likelihood of a PWOUD quitting by a factor of 2 or more and also reduces the frequency of street use and the risk of overdose (51-52). The fraction of PWOUD receiving MAT (at some point during the year) more than doubled during $2003-2016$, rising from less than $20 \%$ to more than $40 \%(5-6,28)$.

One may simulate a future policy intervention to further increase the fraction of PWOUD receiving MAT.

Note that our model does not explicitly represent relapsing by PWOUD that occurs after more than one year of abstinence. Such delayed relapsing would trace through the model implicitly as quitting followed by re-initiation of use and rapid escalation to OUD.

\section{PO street availability, price, and diversion}

PO relative street availability is modeled through a pair of stocks, one representing all apparent PO on the street (both authentic and counterfeit) and the other representing only counterfeit (fentanyl) pills; these stocks are measured in actual or apparent MME. These stocks have inflows of newly diverted PO and newly arriving counterfeit pills. They have outflows of street demand or consumption, driven by the number of PO NMUs (OUD as well as non-OUD). PO relative availability on the street is the ratio of the combined stock to current street demand.

Street availability per se is not tracked in real life, but a closely related measure is average street price. (We model average PO street price per MME as an inverse function of relative availability.) Large, mostly reliable samples of PO street prices may be found at crowdsourcing websites such as StreetRx.com and Bluelight.org $(44-45,53)$. These data suggest that PO street 
price generally decreased from 2007 to 2018, except for a large upward spike during 20112013.

In order to approximate this pattern in the model, we allow the diverted fraction of PO to vary over time, in two ways. First, we assume the existence of a balancing feedback loop, reflecting a profit motive for suppliers (50), in which low current street availability (thus, higher street price) spurs more diversion, while high current availability (lower price) inhibits further diversion.

Second, we assume that interventions had the effect of reducing diversion and street availability during the period 2011-2013, causing the price to spike during those years. One was the introduction of tamper-resistant OxyContin in late $2010(1,10)$. The other was a crackdown on "pill mills" (for example, in Florida and Texas) that dole out large quantities of PO based on fraudulent scripts (54-55). These control efforts had mostly run their course by 2014 . One may, however, simulate other possible future efforts to control diversion.

\section{Heroin initiation, addiction, and quitting}

We model two routes of initiation to heroin: from prior PO NMU and not. Since NSDUH first starting tracking this in 2000, most new heroin users (OUD and non-OUD) have come from prior PO NMU as opposed to coming directly to heroin $(3,43)$.

The historical pattern of heroin initiation was uneven growth from 1990 through the early 2010s followed by decline. The growth through 2010 likely reflects a few factors: social diffusion; the steady decline in heroin price (32-34); and the growth (during 2002-2011) in the non-oral abuse of PO (injecting or inhaling, which typically precede the transition from PO to 
heroin) $(30-31,56)$. Further growth in heroin initiation during 2011-2013 reflects the upward spike in PO price that occurred during those years (44-45), relative to a heroin price that was continuing to decline (10). We model heroin price as an exogenous time series that can be modified when testing future scenarios.

The rapid decline in heroin initiation seen in the data since 2014 likely reflects fear of overdose; heroin user overdoses grew dramatically during this recent period largely due to contamination of street heroin by illicit fentanyl $(4,46)$.

We model two routes of becoming a heroin user with OUD: from prior PO OUD (the more common route) and through escalation from non-OUD heroin use. NSDUH data for 2000-2014 indicate that $50-63 \%$ of heroin users have OUD (43).

Treatment (MAT) affects the rate of quitting for persons with heroin OUD. However, MAT is about $20 \%$ less effective at generating quits in persons with heroin OUD than in persons with PO OUD (57).

\section{Opioid overdoses and overdose deaths}

Heroin users and persons with PO OUD using non-orally (injecting and inhaling) are at a risk of overdosing twice or more that of persons with PO OUD using orally (58) and, we estimate, 2025 times that of non-OUD PO NMUs. Risks for all opioid NMUs (both PO and heroin users) increased after 2013 due to the rise of illicit fentanyl (and even more dangerous analogs such as carfentanil), resulting in a doubling of annual opioid overdose deaths from 2013 to $2017(4,46)$. Recent data suggest that, since 2017 , the growth in opioid overdose deaths has finally slowed and perhaps peaked $(59,60)$. 
For PO NMUs, the illicit fentanyl risk is from look-alike counterfeit pills, and this risk is

calculated in the model by comparing the simulated stock of such counterfeits to the total stock of PO available on the street. For heroin users, the risk is from fentanyl powder that looks identical to heroin. We model the influx of fentanyl pills and fentanyl powder as exogenous time series that can be modified when testing future scenarios.

Most overdose deaths occur at home or otherwise outside a medical facility; this fraction increased during $1999-2015$ from $65 \%$ to $73 \%$ (61). Laypersons thus have a key role to play in administering naloxone to reverse overdoses, and it has been demonstrated that they can do so effectively (62-63). An increasing number of public health departments, pharmacies, and other organizations provide naloxone kits to laypersons. More than 26,000 opioid overdose reversals were reported through mid-2014 by such organizations and more than 8,000 in 2013 alone (64). We estimate that this represented only about $3 \%$ of the potential opportunity for naloxone reversal by laypersons in 2013 , and perhaps $4 \%$ by 2017 . One may simulate a future policy intervention to increase the lay use of naloxone.

\section{Model Testing and Results}

Baseline simulation 1990-2030

We performed a baseline (or "status quo") simulation from 1990 to 2030 assuming no further changes beyond 2020 in any of the model's external inputs other than population growth and aging per Census projections (24). This includes no further decline in the per-capita (and agestandardized) opioid prescription rate, which relative to the 1995 level (=1.0) had risen to 1.75 
by 2010 but was down to 1.3 by 2017 and still falling (27). It also includes no further decrease after 2020 in the average MME dosage prescribed, nor in the price of heroin; and no further increase in the non-oral fraction of PO non-medical use, nor in the influx of fentanyl, nor in the MAT fraction of PWOUD, nor in lay naloxone usage.

Figure 2 presents time graphs for 12 outputs from the baseline run and comparisons with historical data. The fit to history is quantified in Table 1 in terms of the mean absolute error as a percentage of the mean (MAEM), a commonly used metric for such comparisons (19). The MAEM is less than $18 \%$ for all 12 output variables and averages $9 \%$ across the 201 data points they encompass. This may be considered good model performance, especially because some of the survey data are erratic, including data for heroin users, PO and heroin initiation, and PO street price.

$<$ Figure 2 goes about here>

Under the status quo assumptions, the model projects flattening in the number of PO NMUs after 2020, continued gradual decline in persons with PO OUD (Figure 2 panel A), and a decline in heroin users (panel B) reversing the rapid growth of 2005-2015. These patterns reflect low rates of initiation (panel C) due to continued fear of overdosing; as well as fewer persons with PO OUD transitioning to heroin (panels $C$ and D) due to lower simulated PO street price. The lower simulated PO street price (panel E), in turn, reflects less consumption demand due to fewer persons with PO OUD, thus greater relative availability on the street.

Overdose deaths decline gradually after 2020 (panel F) reflecting the decline in PWOUD. But fentanyl remains a scourge, responsible for a great majority of overdose deaths in heroin users, 
as well as more than $50 \%$ of overdose deaths in PO NMUs by the early 2020 s. The latter reflects the greater exposure of PO NMUs to counterfeit pills as the street supply of authentic (diverted) PO declines, reflecting a gradual decline in diversion as PO street demand softens.

Note that the baseline projections of our model are in some cases different from the projections of other previous models (15-16). The other models agree that the prevalence of PO non-medical use is on a steady decline, but whereas we project a decline in heroin use they project a continued increase. Likewise, whereas we project a decline in opioid overdose deaths during the 2020s, they project a continued increase. The apparent peaking in recent overdose deaths data (59-60) may call into question these projections of continued growth made by other models.

Intervention tests 2020-2030

Table 2 presents four categories of intervention that can be tested using the model, along with real-world examples of each. These intervention strategies and tactics have been described by the National Academies committee and other policy analysts (1, 15, 65-69). Of the 11 consensus recommendations in the National Academies report, the only ones that do not fall into one of our four categories are behavioral counseling of pain patients to prevent addiction, and syringe exchanges to reduce disease transmission (1).

$<$ Table 2 goes about here $>$

We have experimented with various plausible magnitudes of intervention, as well as combinations of interventions. Here we consider 5 illustrative tests, all implemented starting in 2020 and maintained through the end of the simulation in 2030: 
1. Reduce the average prescribed opioid MME dose by $20 \%$. (We estimate this would reduce average dose to its 2002 value, and $28 \%$ below its 2011 peak.)

2. Cut PO diversion by $30 \%$. (This would be stronger than the diversion control efforts of 2011-2013 which we estimate cut diversion temporarily by $20 \%$.)

3. Increase the fraction of PWOUD receiving MAT from its baseline $45 \%$ to $65 \%$. (This would likely require improved insurance coverage for office-based MAT as well as improved provider training and support [66-69].)

4. Increase naloxone use by laypersons (for overdoses not treated in medical facilities) from its baseline 4\% to 20\%. (Lay naloxone use expanded six-fold from 2010 to 2015 [64]; here we consider another five-fold expansion, perhaps through multiple strategies [65].)

5. Combine the above four interventions.

Table 3 presents simulated outcomes under these interventions (and the baseline run for comparison) in the year 2030 for three variables: persons with OUD (PWOUD), opioid overdoses seen at hospital emergency departments, and opioid overdose deaths. These are variables for which we have baseline data (see Table 1) and are the three variables in the model that in real life most directly indicate the burden of opioid abuse (8-9). We have also produced graphs showing a variety of outcome variables as they change continuously over time from 2020 to 2030 (see online Appendix). With these outputs, we can tell the following story about each simulation relative to the baseline run: 
$<$ Table 3 goes about here $>$

Reduce average dose by $20 \%$ : Medical user addiction is reduced, as is PO street supply (thus boosting PO street price). The reduction in PO availability causes some PO NMUs to quit and reduces escalation to OUD, while it pushes others (especially those already with OUD) into heroin use; this shift is mostly complete by 2026. Also, the reduction in authentic PO on the street exposes more PO NMUs to counterfeit pills. By 2030, PWOUD are reduced $11 \%$, but total opioid overdoses and deaths are reduced by only $1 \%$, reflecting the shift to heroin and greater exposure to fentanyl.

Cut PO diversion by 30\%: Although this intervention does not affect medical user addiction, it otherwise has consequences like those of the previous intervention. The reduction in PO availability strongly boosts PO NMU quits and prevents escalation to OUD, but also pushes many of those already with OUD into heroin use. By 2030, PWOUD are reduced 16\%, but total overdoses and deaths are reduced by only $1 \%$.

Increase MAT to 65\%: This intervention nicely reduces overdoses and deaths within the first year of implementation, but its longer-term effects are more modest. Most treated PWOUD do not become permanent abstainers, but their frequency of street use and risk of overdose are reduced (51-52). Less frequent PO use means less street demand, resulting in an increase in street availability-which attracts more PO NMUs (more initiation, less quitting). As a result, although the boost in MAT reduces persons with heroin OUD, persons with PO OUD increase, enough to cause a net $1 \%$ increase in total PWOUD by 2030 . Total overdoses and 
deaths are reduced by a net $3 \%$ by 2030 , reflecting reduced frequency of use and reduced exposure to fentanyl.

Increase lay naloxone use to $20 \%$ : This intervention immediately reduces overdose deaths. It does allow PWOUD to stay alive longer, especially heroin users, who are the most exposed to fentanyl and most likely to overdose. It is the only intervention we have tested that leads to some increase in the number of overdoses, reflecting the fact that those once saved from overdose may overdose again. By 2030 , overdose deaths are down $12 \%$ relative to the baseline, but PWOUD are up $2 \%$ and total overdoses by $3 \%$.

Combine the four interventions: Combining the four interventions reduces PWOUD by $24 \%$, overdoses by $4 \%$, and deaths by $18 \%$ by 2030 . This is approximately what one would get from simply summing the individual intervention impacts, an indication that the interventions are complementary rather than mutually interfering or redundant.

\section{Sensitivity testing of intervention findings}

We have tested the sensitivity of intervention findings to two types of uncertainty (see online Appendix). First, we identified 47 input constants in the model for which there is some range of uncertainty around the optimized value. To address this type of uncertainty, we have performed extensive Monte Carlo testing, identified hundreds of "qualifying parameter sets" based on fit-to-history, and then tested the interventions against each of these parameter sets (70). We have determined that the model's policy findings are unaffected by uncertainty of constants, although the numerical results may change somewhat. 
Second, we have also tested against future uncertainty in exogenous inputs (aside from interventions), including future non-oral use of $\mathrm{PO}$, heroin price, and influxes of fentanyl powder and counterfeit pills. We find that the basic policy findings are unaffected by this type of uncertainty as well.

\section{Conclusion}

The opioid epidemic is complex and warrants a systems modeling approach. The significance of the model presented here is that it includes behavioral feedback loops and has greater breadth than other models to date, reproduces the epidemic's entire history along several interacting dimensions, and demonstrates both intended and unintended consequences of policy intervention.

Model testing indicates that no single intervention significantly reduces both persons with OUD and overdose deaths, but this can be accomplished by a combination strategy. At this advanced stage of the opioid epidemic, entering the 2020s, only protective measures like naloxone expansion (or perhaps European-style drug checking services (71)) could significantly reduce overdose deaths.

The model's policy findings are insensitive to uncertainties in inputs, a sign of its robustness. However, it is still a simplified version of reality subject to improvement as are all models. Possible improvements include greater detail in our depictions of medical use, 
diversion, street supply, treatment, relapse, and the fear of overdose, as well as more detailed policy analyses.

\section{Acknowledgments}

We would like to acknowledge the substantial contributions of our colleagues: data analyst Christina Ingersoll, researcher Elizabeth Etherton, methodological advisors John Sterman and Tom Fiddaman, and project supervisor Rayford Etherton.

\section{References}

1. Bonnie RJ, Ford MA, Phillips JK, editors (2017). Pain Management and the Opioid Epidemic: Balancing Societal and Individual Benefits and Risks of Prescription Opioid Use. National Academies Press: Washington, DC.

2. Cicero TJ, Ellis MS, Harney J (2015). Shifting patterns of prescription opioid and heroin abuse in the United States. N Engl J Med 373(18):1789-1790.

3. Jones CM (2013). Heroin use and heroin use risk behaviors among nonmedical users of prescription opioid pain relievers-United States, 2002-2004 and 2008-2010. Drug Alc Dependence 132(1-2):95-100.

4. Pardo B, Taylor J, Caulkins JP, Kilmer B, Reuter P, Stein BD (2019). The future of fentanyl and other synthetic drugs. RAND Corporation, 265 pp. Available at: 
https://www.rand.org/content/dam/rand/pubs/research reports/RR3100/RR3117/RAND

\section{RR3117.pdf}

5. Jones CM, Campopiano M, Baldwin G, McCance-Katz E (2015). National and state treatment need and capacity for opioid agonist medication-assisted treatment. Am J Public Health 105(8):e55-e63.

6. Alderks CE (2017). Trends in the use of methadone, buprenorphine, and extended-release naltrexone at substance abuse treatment facilities: 2003-2015 (update). Substance Abuse and Mental Health Services Administration, August 22, 2017.

7. Hedegaard H, Miniño AM, Warner M (2019). Drug overdose deaths in the United States, 1999-2017. Hyattsville, MD: National Center for Health Statistics Data Brief No. 329, Dec. 2017. Available at: https://www.cdc.gov/nchs/products/databriefs/db329.htm

8. Florence CS, Zhou C, Luo F, Xu L (2016). The economic burden of prescription opioid overdose, abuse, and dependence in the United States, 2013. Medical Care 54(10):901-906.

9. Rhyan CN (2017). The potential societal benefit of eliminating opioid overdoses, deaths, and substance use disorders exceeds $\$ 95$ billion per year. Altarum/Center for Value in Health Care, November 16, 2017. Available at:

https://altarum.org/sites/default/files/uploaded-publication-files/Research-Brief OpioidEpidemic-Economic-Burden.pdf

10. Evans WN, Lieber E, Power P (2019). How the reformulation of OxyContin ignited the heroin epidemic. Rev Econ Stat 101:1-15. 
11. Weiner J, Murphy SM, Behrends C (2019). Expanding access to naloxone: a review of distribution strategies. Penn LDI/CHERISH Issue Brief, May 2019. Available at: https://ldi.upenn.edu/brief/expanding-access-naloxone-review-distribution-strategies

12. Frank RG, Humphreys K, Pollack HA (2018). Does naloxone availability increase opioid abuse? The case for skepticism. Health Affairs Blog, March 19, 2018. Available at: https://www.healthaffairs.org/do/10.1377/hblog20180316.599095/full

13. Wakeland W, Nielsen A, Geissert P (2015). Dynamic model of nonmedical opioid use trajectories and potential policy interventions. Am J Drug Alc Abuse 41(6):508-518.

14. Wakeland W, Nielsen A, Schmidt T, McCarty D, Webster L, Fitzgerald J, Haddox JD (2013). Modeling the impact of simulated educational interventions in the use and abuse of pharmaceutical opioids in the United States: a report on initial efforts. Health Educ Behav 40:74S-86S.

15. Pitt AL, Humphreys K, Brandeau ML (2018). Modeling health benefits and harms of public policy responses to the US opioid epidemic. Am J Pub HIth 108(10):1394-1400.

16. Chen Q, Larochelle MR, Weaver DT, Chhatwal J, and others (2019). Prevention of prescription opioid misuse and projected overdose deaths in the United States. JAMA Open Network 2(2): e187621.

17. Jalali M, Botticelli M, Hwang R, Koh HK, McHugh RK (2019). The opioid crisis: a contextual framework and call for systems science research. SSRN (https://www.ssrn.com/), ID 3407952, posted 25 June 2019. 
18. Sharareh N, Sabounchi SS, McFarland M, Hess R (2019). Evidence of modeling impact in development of policies for controlling the opioid epidemic and improving public health: a scoping review. Substance Abuse: Research and Treatment 13:1-10. Available at:

\section{https://doi.org/10.1177/1178221819866211}

19. Sterman JD (2000). Business Dynamics: Systems Thinking and Modeling for a Complex World. Boston: McGraw-Hill.

20. Homer J, Hirsch G (2006). System dynamics modeling for public health: background and opportunities. Am J Public HIth 96(3):452-458.

21. Homer JB (1993). A system dynamics model of national cocaine prevalence. Sys Dyn Rev 9(1):49-78.

22. Hirsch G, Homer J, Tomoaia-Cotisel A, editors (2015). System dynamics applications to health and health care. Sys Dyn Rev (virtual issue), January 2015. Available at: http://onlinelibrary.wiley.com/journal/10.1002/(ISSN)1099-

\section{7/homepage/VirtuallssuesPage.html}

23. U.S. Census Bureau (2011). Statistical Abstract of the United States: 2012 (131 $11^{\text {st }}$ edition). Table 7: Resident population by sex and age: 1980 to 2010. Washington DC: US Census Bureau. Available at: https://www.census.gov/library/publications/2011/compendia/statab/131ed/population.ht $\underline{\mathrm{ml}}$

24. U.S. Census Bureau (2018). Projected 5-year age groups and sex composition: main projections series for the United States, 2017-2060. Table 3: Projected 5-year age groups 
and sex composition of the population. Washington DC: US Census Bureau. Available at: https://www.census.gov/data/tables/2017/demo/popproj/2017-summary-tables.html

25. Pezalla EJ, Rosen D, Erensen JG, Haddox JD, Mayne TJ (2017). Secular trends in opioid prescribing in the USA. J Pain Research 10:383-387.

26. Centers for Disease Control and Prevention (CDC) (2018). U.S. opioid prescribing rate maps. Table 1: Total number and rate of opioid prescriptions dispensed, United States, 2006-2017. Available at: https://www.cdc.gov/drugoverdose/maps/rxrate-maps.html

27. Dasgupta N, Kramer ED, Zalman M-A, Carino Jr S, Smith MY, Haddox JD, Wright IV C (2006). Association between non-medical and prescriptive usage of opioids. Drug Alc Depend $82: 135-142$.

28. U.S. Department of Justice, Drug Enforcement Administration (DOJ/DEA), Diversion Control Division (2018). ARCOS retail drug summary reports. Available at: https://www.deadiversion.usdoj.gov/arcos/retail drug summary/

29. US Centers for Medicare and Medicaid Services (CMS) (2015). Opioid morphine equivalent conversion factors. Available at: www.cms.gov/Medicare/Prescription-Drug-

\section{Coverage/PrescriptionDrugCovContra/Downloads/Opioid-Morphine-EQ-Conversion-}

\section{Factors-March-2015.pdf}

30. Jones CM, Christensen A, Gladden RM (2017). Increases in prescription opioid injection abuse among treatment admissions in the United States, 2004-2013. Drug Alc Dependence 176:89-95. 
31. Substance Abuse and Mental Health Services Administration (SAMHSA) (2018). Treatment Episode Data Set (annual). Available at: $\underline{\text { https://datafiles.samhsa.gov/info/browse-studies- }}$ $\underline{\text { nid3454 }}$

32. Unick G, Rosenblum D, Mars S, Ciccarone D (2014). The relationship between US heroin market dynamics and heroin-related overdose, 1992-2008. Addiction 109(11);1889-1898.

33. U.S. Department of Justice, Drug Enforcement Administration (DEA) (2015). 2013 National Level STRIDE Price and Purity Data. DEA-DCW-DIR-068-15. September 2015. Available at: https://ndews.umd.edu/sites/ndews.umd.edu/files/pubs/2013\%20National\%20Level\%20ST RIDE\%20Price\%20and\%20Purity\%20Data.pdf

34. U.S. Department of Justice, Drug Enforcement Administration (DEA) (2018). 2018 National Drug Threat Assessment. DEA-DCT-DIR-032-18. October 2018. Available at: https://www.dea.gov/sites/default/files/2018-11/DIR-03218\%202018\%20NDTA\%20final\%20low\%20resolution.pdf

35. National Forensic Laboratory Information System (NFLIS) (2017). NFLIS brief: fentanyl, 2001-2015. US DOJ/DEA, March 2017. Available at:

https://www.nflis.deadiversion.usdoj.gov/DesktopModules/ReportDownloads/Reports/NFL ISFentanylBrief2017.pdf

36. National Forensic Laboratory Information System (NFLIS) (2017). NFLIS brief: fentanyl and fentanyl-related substances reported in NFLIS, 2015-2016. US DOJ/DEA, October 2017, updated March 2018. Available at: 
https://www.nflis.deadiversion.usdoj.gov/DesktopModules/ReportDownloads/Reports/113

$\underline{50}$ R2 NFLIS Research Brief Fentanyl.pdf

37. Hasegawa K, Espinola JA, Brown DFM, Camargo CA (2014). Trends in U.S. emergency department visits for opioid overdose, 1993-2010. Pain Medicine 15:1765-1770.

38. Substance Abuse and Mental Health Services Administration (SAMHSA) (2019). Key substance use and mental health indicators in the United States: Results from the 2018 National Survey on Drug Use and Health (HHS Pub. PEP19-5068, NSDUH Series H-54). Rockville, MD: Center for Behavioral Health Statistics and Quality, SAMHSA.

39. Jones CM (2016). Assessing the relationship between prescription opioid nonmedical use and heroin use. DHHS/OASPE, slide presentation. Available at:

https://www.radars.org/system/events/RADARS\%20System\%202016\%20Annual\%20Meetin g Jones.pdf.tmp

40. Muhuri PK, Gfroerer JC, Davies MC (2013). Associations of nonmedical pain reliever use and initiation of heroin use in the United States. CBHSQ Data Review. Substance Abuse and Mental Health Services Administration, August 2013. Available at:

https://www.samhsa.gov/data/sites/default/files/DR006/DR006/nonmedical-pain-relieveruse-2013.htm

41. Compton WM, Volkow ND (2006). Major increases in opioid analgesic abuse in the United States: concerns and strategies. Drug Alc Dependence 81:103-107. 
42. Kolodny A, Courtwright DT, Hwant CS, Kreiner P, Eadie JL, Clark TW, Alexander GC (2015). The prescription opioid and heroin crisis: a public health approach to an epidemic of addiction. Ann Rev Pub Health 36:559-574.

43. Substance Abuse and Mental Health Services Administration (SAMHSA) (2018). National Survey on Drug Use and Health (annual). Available at: https://datafiles.samhsa.gov/info/browse-studies-nid3454

44. StreetRx.com (2018). Available at: www.streetrx.com

45. Bluelight.org (2018). Available at: https://www.bluelight.org/xf/

46. National Institute on Drug Abuse (NIDA) (2018). Overdose death rates. Available at: https://www.drugabuse.gov/related-topics/trends-statistics/overdose-death-rates; see also: https://wonder.cdc.gov/

47. Homer J (2020). Reference guide for the opioid epidemic simulation model (version $2 u$ ). February 2020. Available at: https://pdxscholar.library.pdx.edu/sysc fac/153/

48. Johnston LD, Miech RA, O’Malley PM, Bachman JG, Schulenberg JE, Patrick ME (2019). Monitoring the future national survey results on drug use, 1975-2018: overview, key findings on adolescent drug use. University of Michigan Institute for Social Research: Ann Arbor, MI. Available at https://eric.ed.gov/?id=ED594190

49. Edlund MJ, Martin BC, Russo JE, Devries A, Braden JB, Sullivan MD (2014). The role of opioid prescription in incident opioid abuse and dependence among individuals with chronic non-cancer pain. Clin J Pain 30(7):557-564. 
50. Reuter P, ed. (2010). Understanding the Demand for Illegal Drugs. National Academies Press: Washington, DC. 124 pp. Available at:

\section{https://www.nap.edu/catalog/12976/understanding-the-demand-for-illegal-drugs}

51. National Institute on Drug Abuse (NIDA) (2018). Medications to treat opioid use disorder. 47pp. Available at: https://www.drugabuse.gov/publications/research-

\section{reports/medications-to-treat-opioid-addiction/overview}

52. Connery HS (2015). Medication-assisted treatment of opioid use disorder: review of the evidence and future directions. Harvard Rev Psychiatry 23(2):63-75.

53. Dasgupta N, Freifeld C, Brownstein JS, Menone CM, and others (2013). Crowdsourcing black market prices for prescription opioids. J Med Internet Res 15(8):e178. doi:10.2196/jmir.2810.

54. Rutkow L, Change H-Y, Daubresse M, Webster DW, and others (2015). Effect of Florida's prescription drug monitoring program and pill mill laws on opioid prescribing and use. JAMA Intern Med 175(10):1642-1649.

55. Lyapustina T, Rutkow L, Chang H-Y, Daubresse M, and others (2016). Effect of a "pill mill" law on opioid prescribing and utilization: the case of Texas. Drug Alc Dependence 159:190197.

56. Carlson RG, Nahhas RW, Martins SS, Daniulaityte R (2016). Predictors of transition to heroin use among initially non-opioid dependent illicit pharmaceutical opioid users: a natural history study. Drug Alc Depend 160:127-134. 
57. Potter JS, Marino EN, Hillhouse MP, Nielsen S, Wiest K, Canamar CP, and others (2013). Buprenorphine/naloxone and methadone maintenance treatment outcomes for opioid analgesic, heroin, and combined users: findings from Starting Treatment with Agonist Replacement Therapies (START). J Stud Alc Drugs 74:605-613.

58. Green JL, Bartelson BB, Le Lait MC, Roland CL, Masters ET, Mardekian J, Bailey JE, Dart RC (2017). Medical outcomes associated with prescription opioid abuse via oral and non-oral routes of administration. Drug Alc Dependence 175:140-145.

59. Hedegaard H, Miniño AM, Warner M (2020). Drug overdose deaths in the United States, 1999-2018. Hyattsville, MD: National Center for Health Statistics Data Brief No. 356, Jan. 2020. Available at: https://www.cdc.gov/nchs/products/databriefs/db356.htm

60. US News \& World Report (2020). Opioid overdose deaths down $5 \%$ from state's peak in 2016. Associated Press, Wire Service Content, Feb. 12, 2020. Available at: https://www.usnews.com/news/best-states/massachusetts/articles/2020-02-12/opioidoverdose-deaths-down-5-from-states-peak-in-2016

61. Mack KA, Jones CM, Ballesteros MF (2017). Illicit drug use, illicit drug use disorders, and drug overdose deaths in metropolitan and nonmetropolitan areas-United States. Morbidity and Mortality Weekly Report 66(19):1-12. Available at: https://www.cdc.gov/mmwr/volumes/66/ss/ss6619a1.htm

62. Adams JM (2018). Increasing naloxone awareness and use: the role of health care practitioners. JAMA (online), April 5, 2018, E1-E2. doi: 10.1001/jama.2018.4867. 
63. Lynn RR, Galinkin JL (2018). Naloxone dosage for opioid reversal: current evidence and clinical implications. Therap Advances in Drug Safety 9(1):63-88.

64. Wheeler E, Jones TS, Gilbert MK, Davidson PJ (2015). Opioid overdose prevention programs providing naloxone to laypersons-United States, 2014. MMWR 64(23):631-634.

65. Weiner J, Murphy SM, Behrends C (2019). Expanding access to naloxone: a review of distribution strategies. U Penn: LDI/CHERISH Issue Brief, 6 pp. Available at: https://Idi.upenn.edu/brief/expanding-access-naloxone-review-distribution-strategies

66. Volkow ND, Frieden TR, Hyde PS, Cha SS (2014). Medication-assisted therapies-tackling the opioid-overdose epidemic. N Engl J Med 370(22):2063-2066.

67. Hinde J, Hayes J, Mark T, Bernstein S, Karon SL (2017). State and local policy levers for increasing treatment and recovery capacity to address the opioid epidemic: final report. RTI International: Research Triangle Park, NC. For ASPE/DHHS. September 29, 2017. Available at: https://aspe.hhs.gov/basic-report/state-and-local-policy-levers-increasing-treatmentand-recovery-capacity-address-opioid-epidemic-final-report

68. Orgera K, Tolbert J (2019). The opioid epidemic and Medicaid's role in facilitating access to treatment. Kaiser Family Foundation, May 2019. Available at: https://www.kff.org/medicaid/issue-brief/the-opioid-epidemic-and-medicaids-role-infacilitating-access-to-treatment/

69. Hernàndez EJM (2017). Increasing access to medication-assisted treatment for opioid use disorders: estimating costs, supply, and the effects of insurance expansions. PhD 
Dissertation, Pardee RAND Graduate School. Available at:

https://www.rand.org/pubs/rgs dissertations/RGSD404.html

70. Wakeland W, Homer J (2020). Addressing parameter uncertainty in SD models with fit-tohistory and Monte Carlo sensitivity methods and with application to an opioid epidemic model. Proc. $38^{\text {th }}$ Int l Conf of the Syst Dyn Soc, Bergen, Norway. Available at: https://works.bepress.com/wayne wakeland/121/

71. Brunt T (2017). Drug checking as a harm reduction tool for recreational drug users: opportunities and challenges. European Monitoring Centre for Drugs and Drug Addiction (EMCDDA), October 30, 2017. Available at: http://www.emcdda.europa.eu/system/files/attachments/6339/EuropeanResponsesGuide 2017 BackgroundPaper-Drug-checking-harm-reduction 0.pdf 


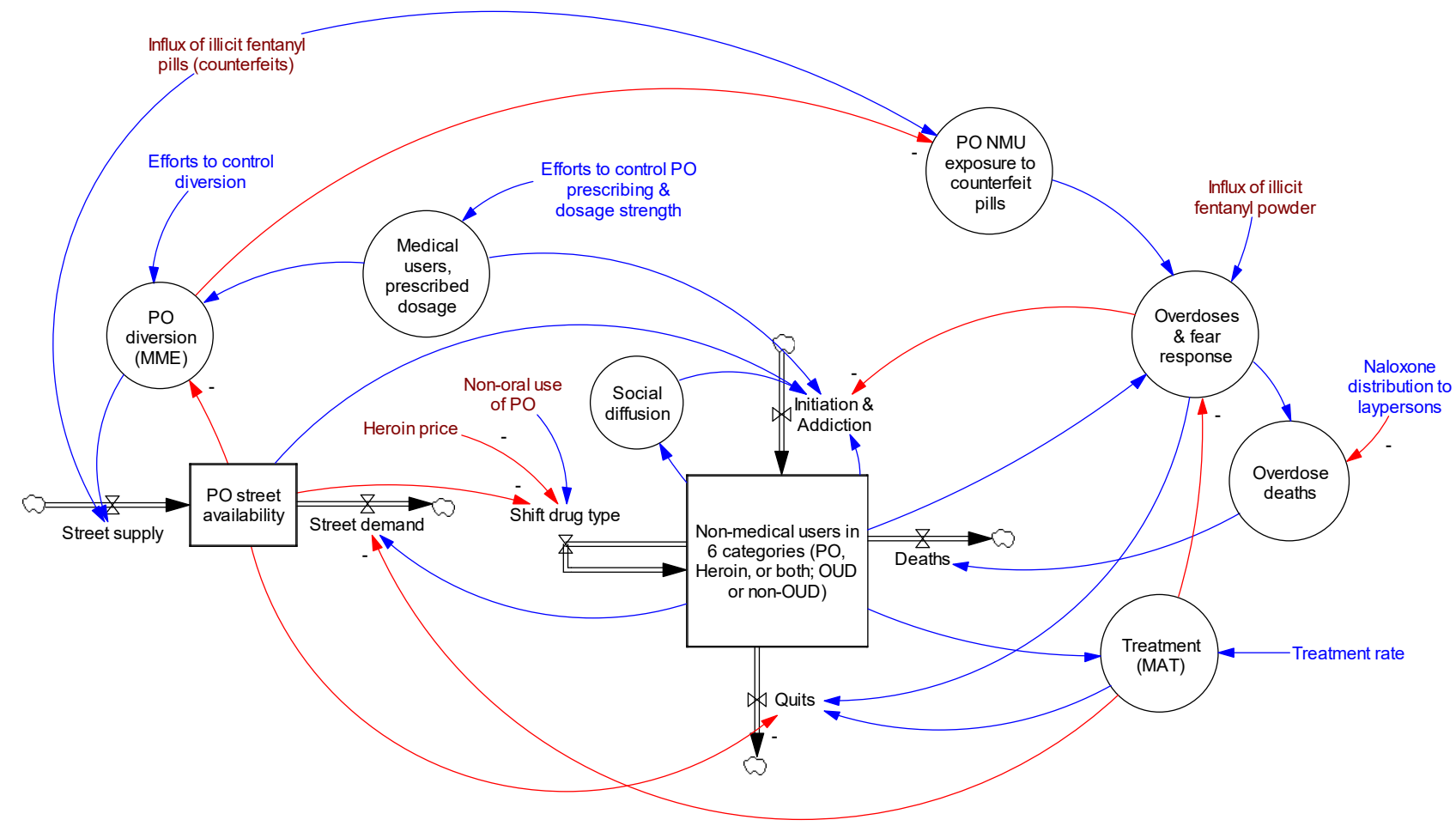

Figure 1. Model overview diagram, showing the model's primary concepts and their causal connections. Rectangle=stock variable; Thick arrow with valve symbol=flow variable;

Circle=other calculated variable; Blue text=intervention input variable; Brown text=other input variable; Blue arrow= causal link with positive polarity; Red arrow with minus sign=causal link with negative polarity; $\mathrm{PO}=$ prescription opioids; $\mathrm{NMU}=$ non-medical users; $\mathrm{OUD}=$ opioid use disorder; $\mathrm{MME}=$ milligrams morphine equivalent; MAT=medication-assisted treatment. 
Table 1. Longitudinal data sources and baseline run fit to history in terms of mean absolute error as percentage of historical mean (MAEM \%)

\begin{tabular}{|c|c|c|c|c|}
\hline Variable & Datasets and Sources & Year range & $\begin{array}{c}\text { \# of data } \\
\text { points }\end{array}$ & MAEM \% \\
\hline \multicolumn{5}{|c|}{ Data used for calibration of model inputs } \\
\hline US population ages $20-39,40-59,60+$ & US Census tables (23-24) & $1990-2030$ & 45 & \multirow{8}{*}{$\begin{array}{c}\text { (not } \\
\text { applicable) }\end{array}$} \\
\hline PO scripts & IQVIA NPA/Xponent (25-26) & $1992-2017$ & 26 & \\
\hline PO script mg. morphine equiv. (MME) & ARCOS (27-29) & $1994-2016$ & 23 & \\
\hline Persons with OUD treated & N-SSATS, ARCOS $(6,28)$ & $2003-2016$ & 14 & \\
\hline \% PO OUD inject, other non-oral route & TEDS (30-31) & $1995-2014$ & 40 & \\
\hline Avg heroin street price per pure mg & STRIDE (32-34) & $1993-2015$ & 21 & \\
\hline Illicit fentanyl trend (lab reports) & NFLIS (35-36) & $2001-2016$ & 16 & \\
\hline ED visits for opioid overdose & NHAMCS (37) & $1993-2010$ & 9 & \\
\hline \multicolumn{5}{|c|}{ Data used for comparison of model outputs with history } \\
\hline PO total NMUs & NSDUH $(13,38-39)$ & $1995-2018$ & 24 & $6.4 \%$ \\
\hline PO NMUs with OUD & $\operatorname{NSDUH}(5,13,38-40)$ & 2000-2017 & 18 & $9.0 \%$ \\
\hline PO NMU initiates & $\operatorname{NSDUH}(13,37,41-42)$ & $1990-2018$ & 27 & $10.3 \%$ \\
\hline Heroin total users & NSDUH $(38-40,43)$ & $1990-2018$ & 19 & $12.4 \%$ \\
\hline Heroin addicted users & NSDUH $(39-40,43)$ & $2000-2014$ & 14 & $9.0 \%$ \\
\hline Heroin initiates & NSDUH (38) & $2002-2018$ & 17 & $17.8 \%$ \\
\hline$\%$ Heroin users also PO NMU & NSDUH (43) & $1990-2016$ & 7 & $13.9 \%$ \\
\hline$\%$ Heroin initiates previously PO NMU & $\operatorname{NSDUH}(3,43)$ & $2000-2016$ & 8 & $10.1 \%$ \\
\hline Avg PO street price per MME & StreetRx, Bluelight $(29,44-45)$ & $2007-2018$ & 12 & $17.9 \%$ \\
\hline OD deaths from $\mathrm{PO}$ & WONDER (46) & $1999-2016$ & 18 & $5.2 \%$ \\
\hline OD deaths from illicit opioids & WONDER (46) & $1999-2016$ & 18 & $3.5 \%$ \\
\hline OD deaths total & WONDER (46) & 1999-2017 & 19 & $3.7 \%$ \\
\hline \multicolumn{5}{|l|}{ Key to dataset acronyms: } \\
\hline \multicolumn{5}{|c|}{ NPA: National Prescription Audit (IQVIA, Inc.) } \\
\hline \multicolumn{5}{|c|}{ ARCOS: Automated Reports and Consolidated Ordering System (DEA) } \\
\hline \multicolumn{5}{|c|}{ N-SSATS: National Survey of Substance Abuse Treatment Services (SAMHSA) } \\
\hline \multicolumn{5}{|c|}{ TEDS: Treatment Episode Data Set (SAMHSA) } \\
\hline \multicolumn{5}{|c|}{ STRIDE: System to Retrieve Information from Drug Evidence (DEA) } \\
\hline \multicolumn{5}{|c|}{ NFLIS: National Forensic Laboratory Information System (DEA) } \\
\hline \multicolumn{5}{|c|}{ NHAMCS: National Hospital Ambulatory Medical Care Survey (CDC) } \\
\hline \multicolumn{5}{|c|}{ NSDUH: National Survey of Drug Use and Health (SAMHSA) } \\
\hline \multicolumn{5}{|c|}{ WONDER: Wide-ranging Online Data for Epidemiologic Research (CDC) } \\
\hline
\end{tabular}


(a)

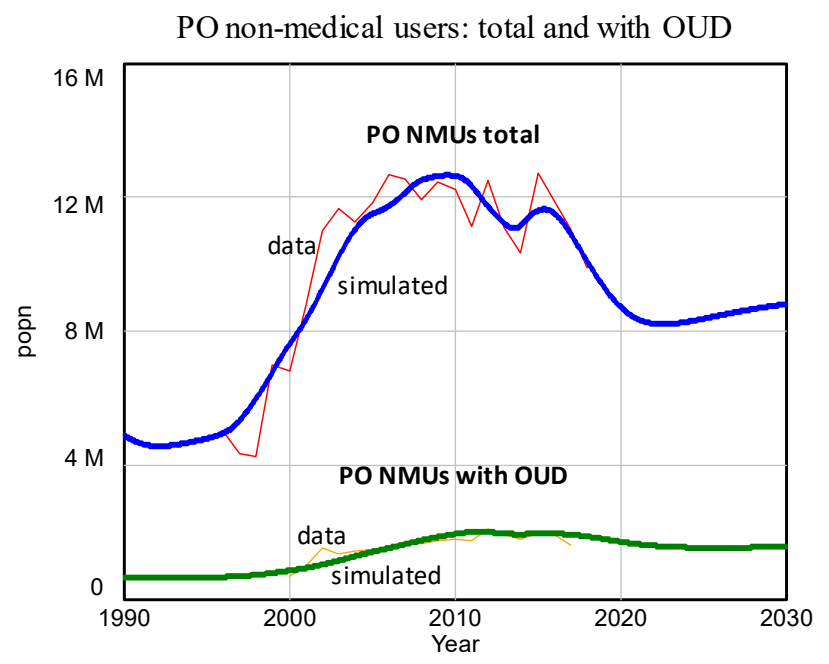

(c)

Initiates per year to $\mathrm{PO}$ and heroin

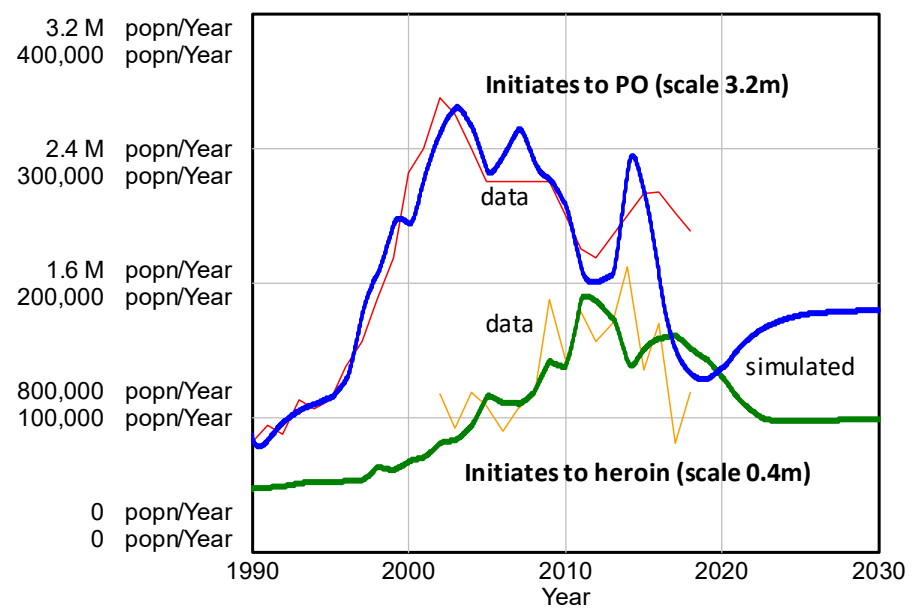

(b)

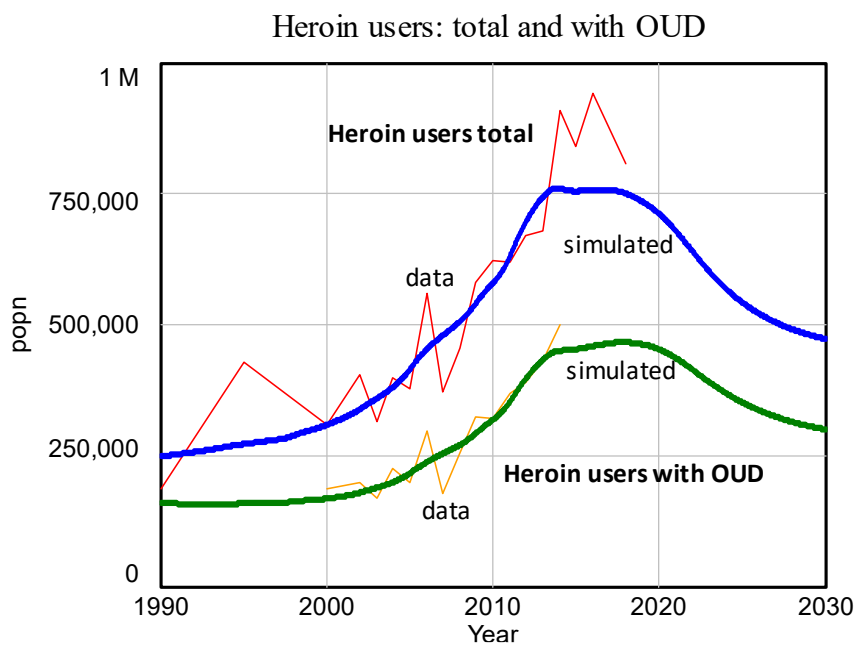

(d)

Fraction of heroin users and initiates also PO NMU

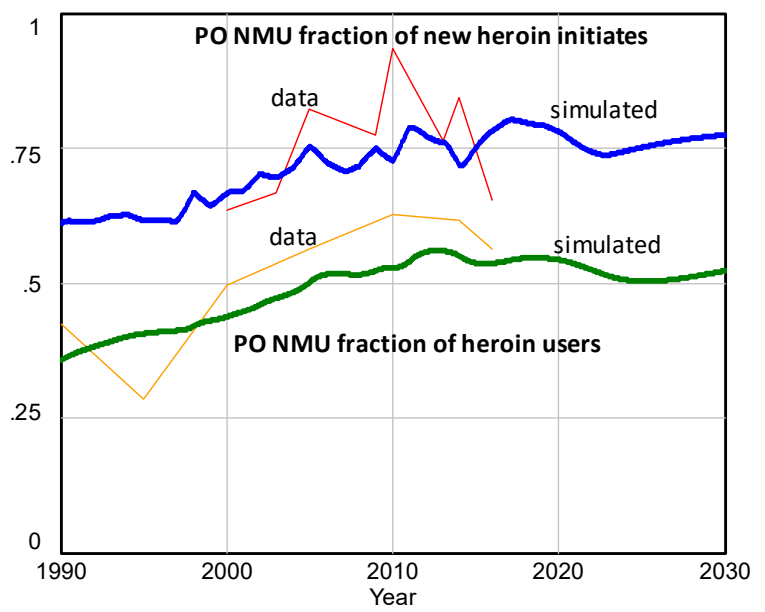


(e)

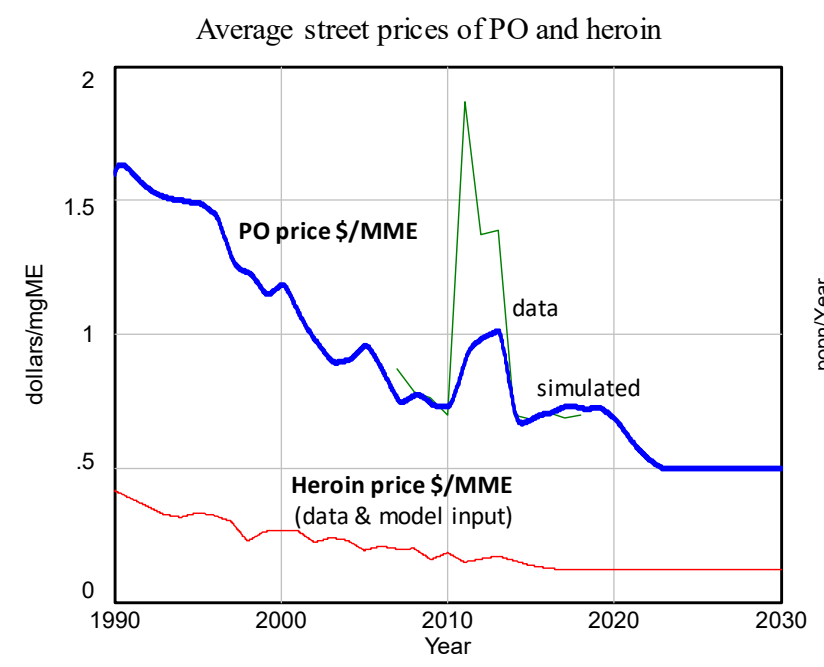

(f)

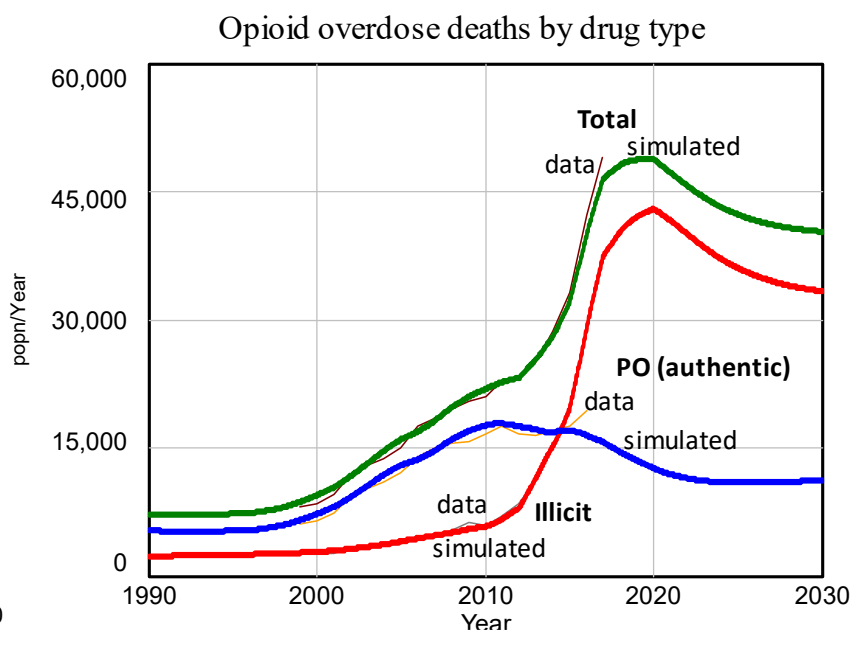

Figure 2. Model outputs compared with historical data and projected under baseline assumptions to 2030. (a) PO nonmedical users, total and OUD; (b) Heroin users, total and OUD; (c) New initiates to PO nonmedical use and heroin use; (d) Fractions of heroin users and heroin initiates who are also PO NMUs; (e) Average PO and heroin street prices per MME; (f) Overdose deaths from prescription opioids, illicit opioids, and all opioids; $\mathrm{PO}=$ prescription opioids;

NMU=non-medical users; OUD=opioid use disorder. 
Table 2. Intervention categories and examples. MAT=medication-assisted treatment;

$\mathrm{ED}=$ emergency department.

\begin{tabular}{|c|c|}
\hline Intervention category & Examples \\
\hline \multirow{5}{*}{$\begin{array}{l}\text { Efforts to control PO prescribing \& } \\
\text { dosage strength }\end{array}$} & Provider education \\
\hline & Prescription guidelines \\
\hline & Electronic decision support \\
\hline & Prescription drug monitoring programs \\
\hline & Prescription drug rescheduling (to reduce refills) \\
\hline \multirow{4}{*}{ Efforts to control diversion } & Patient and public education \\
\hline & Abuse-deterrent formulations \\
\hline & Rx drug take-back programs \\
\hline & Law enforcement crackdowns \\
\hline \multirow{5}{*}{$\begin{array}{l}\text { Efforts to expand and improve } \\
\text { addiction treatment }\end{array}$} & Improve insurance coverage of MAT \\
\hline & $\begin{array}{l}\text { Mandate MAT access in hospitals, prisons, and } \\
\text { substance abuse programs }\end{array}$ \\
\hline & Mandate MAT training for medical providers \\
\hline & Expand psychosocial supports for treated addicts \\
\hline & Refer patients to MAT after ED overdose rescue \\
\hline \multirow{4}{*}{$\begin{array}{l}\text { Efforts to reduce risks of deadly } \\
\text { overdose }\end{array}$} & $\begin{array}{l}\text { Naloxone laws and subsidies facilitating distribution } \\
\text { through pharmacies and medical providers }\end{array}$ \\
\hline & Naloxone training for first responders and laypersons \\
\hline & Laws allowing supervised injection facilities \\
\hline & $\begin{array}{l}\text { Laws allowing drug checking (for adulteration and } \\
\text { counterfeits) }\end{array}$ \\
\hline
\end{tabular}


Table 3. Intervention testing outcomes as of 2030. OUD=opioid use disorder; ED=emergency department.

\begin{tabular}{|l|c|c|c|c|c|c|}
\cline { 2 - 7 } \multicolumn{1}{c|}{} & \multicolumn{3}{c|}{ Simulated results as of 2030 } & \multicolumn{3}{c|}{ Percent change from baseline } \\
\hline Simulation & $\begin{array}{c}\text { Persons } \\
\text { with OUD } \\
\text { (thou.) }\end{array}$ & $\begin{array}{c}\text { Overdoses } \\
\text { seen at ED }\end{array}$ & $\begin{array}{c}\text { Overdose } \\
\text { deaths }\end{array}$ & $\begin{array}{c}\text { Persons } \\
\text { with OUD }\end{array}$ & $\begin{array}{c}\text { Overdoses } \\
\text { seen at ED }\end{array}$ & $\begin{array}{c}\text { Overdose } \\
\text { deaths }\end{array}$ \\
\hline Baseline & 1,694 & 154,710 & 40,323 & & & $-1.3 \%$ \\
\hline Avg MME dose down 20\% & 1,510 & 152,686 & 39,796 & $-10.9 \%$ & $-1.3 \%$ \\
\hline Diversion control 30\% & 1,428 & 153,076 & 39,897 & $-15.7 \%$ & $-1.1 \%$ & $-1.1 \%$ \\
\hline Treatment rate 65\% (from 45\%) & 1,713 & 150,095 & 39,120 & $1.1 \%$ & $-3.0 \%$ & $-3.0 \%$ \\
\hline Naloxone lay use 20\% (from 4\%) & 1,728 & 159,228 & 35,302 & $2.0 \%$ & $2.9 \%$ & $-12.5 \%$ \\
\hline All 4 policies combined & 1,285 & 148,395 & 32,900 & $-24.1 \%$ & $-4.1 \%$ & $-18.4 \%$ \\
\hline
\end{tabular}

